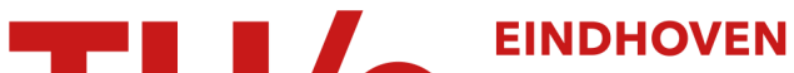 \\ UNIVERSITY OF \\ TECHNOLOGY
}

\section{Application of a boiling water loop model to boiling sodium}

\author{
Citation for published version (APA): \\ Bogaardt, M., \& Spigt, C. L. (1967). Application of a boiling water loop model to boiling sodium. Nuclear \\ Engineering and Design, 5(4), 465-476. https://doi.org/10.1016/0029-5493(67)90104-5
}

DOI:

10.1016/0029-5493(67)90104-5

Document status and date:

Published: 01/01/1967

\section{Document Version:}

Publisher's PDF, also known as Version of Record (includes final page, issue and volume numbers)

\section{Please check the document version of this publication:}

- A submitted manuscript is the version of the article upon submission and before peer-review. There can be important differences between the submitted version and the official published version of record. People interested in the research are advised to contact the author for the final version of the publication, or visit the $\mathrm{DOI}$ to the publisher's website.

- The final author version and the galley proof are versions of the publication after peer review.

- The final published version features the final layout of the paper including the volume, issue and page numbers.

Link to publication

\section{General rights}

Copyright and moral rights for the publications made accessible in the public portal are retained by the authors and/or other copyright owners and it is a condition of accessing publications that users recognise and abide by the legal requirements associated with these rights.

- Users may download and print one copy of any publication from the public portal for the purpose of private study or research.

- You may not further distribute the material or use it for any profit-making activity or commercial gain

- You may freely distribute the URL identifying the publication in the public portal.

If the publication is distributed under the terms of Article 25fa of the Dutch Copyright Act, indicated by the "Taverne" license above, please follow below link for the End User Agreement:

www.tue.nl/taverne

Take down policy

If you believe that this document breaches copyright please contact us at:

openaccess@tue.nl

providing details and we will investigate your claim. 


\title{
APPLICATION OF A BOILING WATER LOOP MODEL TO BOILING SODIUM
}

\author{
M. BOGAARDT and C. L. SPIGT \\ Technological University of Eindhoven. Eindhoven. The Netherlands
}

Received 13 May 1967

\begin{abstract}
In this report results are given of an analytical study on the applicability to a boiling sodium system of existing physical-mathematical formulations for the performance characteristics of a boiling water system under steady or transient conditions. Furthermore, the effect of liquid superheat on the calculated performance characteristics has been evaluated. It is shown that the application of theoretical models developed for water systems to liquid metal systems does not lead to difficulties but that the effect of liquid superheat should be taken into account in case appreciable superheats are found to occur.
\end{abstract}

\section{INTRODUCTION}

In the Technological Laboratory of Reactor Centrum Nederland at Petten a research programme has been started to investigate the behaviour of sodium under accident conditions. For this purpose a $350 \mathrm{~kW}$ experimental liquid sodium loop is under construction.

The experimental programme is to be backed up by theoretical studies. The first step has been to determine if the models used for describing the dynamics of boiling water systems can be applied in the case of boiling sodium, bearing in mind the large difference in the physical proper ties of the two liquids. It is also of inter est to know if liquid superheat will affect the dynamic behaviour of the sodium system to any great extent. The same geometry has been adopted for the boiling sodium system as was used for the boiling water system at the Technological University at Eindhoven, thereby facilitating comparison of results. In the analysis attention is given to the dynamic characteristics of sodium systems with natural as well as forced circulation.

\section{THEORY}

Many physical-mathematical formulations have been reported in literature attempting to describe and to calculate the performance char acteristics of a two-phase flow system under stationary or transient conditions or to analyze particular phenomena observed such as, for instance, the occurrence of severe hydraulic oscillations. In the past few years a new approach to these problems has been developed in the Laboratory for Heat Transfer and Reactor Engineering of the Technological University of Eindhoven. This theory was recently described by Spigt [1] and has been used for the present study.

The approach starts by formulating the four basic equations of motion for the two-phase flow. These equations are formed by the laws of the conservation of mass, momentum and energy of the mixture and an equation for the number density distribution of bubbles describing the transport of steam in the liquid phase. The number density distribution of bubbles is governed by the process of bubble formation and diffusion, demixing effects near the wall, convection of bubbles, interaction effects between adjacent bubbles, and growth of the bubbles in the mixture. These four basic equations have been formulated for a coolant channel of concentric annular shape as a function of the three independent variables, i.e. the time, $t$, the coordinate along the coolant channel, $z$, and the radial coordinate, $r$. To these four equations, the equations of state have been added. They are expressions for the physical quantities of the fluid as a function of the local temperatures. The quantities of importance are the density of the vapour and liquid phases, the specific heat, the heat of evaporation and the change in pressure with temperature under saturated conditions. In the approach under discussion these physical quantities vary along 
the coolant channel so any pressure and temperature effects along the coolant channel and compressibility effects are taken into account.

For design calculations the basic equations have been integrated with respect to $r$ between the limits of the inner and outer radius of the annular coolant channel. It was shown by Spigt [1] that this integration can be performed by introducing empirical or theoretical correlations taking into account the radial variations of the flow quantities. The three most important correlations are those (a) for the slip ratio, (b) for the two-phase friction force and (c) for the heat division parameter $\kappa$ which denotes the fraction of the local heat input that is supplied to the steam phase. Besides, other correlations are needed for an accurate evaluation of the performance characteristics of a boiler. $\kappa$ has to be defined along the length of the coolant channel. By means of $\kappa$ any superheating in the bulk boiling region or any subcooled boiling can be introduced.

The assumption normally made that the subcooled region is not at thermodynamic equilibrium and that the bulk boiling region is in complete thermodynamic equilibrium has been abandoned in this study. This assumption appears to have been made fairly arbitrarily. The main advantage of the proposed choice for the parameter is that only a single set of equations is used for the entire channel and that the approach can be used for any two-phase flow system.

In the study special attention was given to the formulation of the boundary conditions for the boiling channel and thus to the describing equations, which introduce the characteristics of the other parts of the system, e.g. the condensor, downcomer, pump, etc. A detailed formulation of the boundary conditions was obtained by setting up the conservation laws for the external parts of the test circuit.

For studying the dynamic behaviour of a twophase flow system the describing equations have been made dimensionless. This procedure holds certain advantages, such as a more readily apparent comparison between various operating conditions, geometries and working fluids. After that the equations have been linearised with respect to small deviations from the steady state. Then a study is made of the response to a sinusoidal modulation in the controlling variables, e.g. heat input, heat removal or mass flow. In this way transfer functions may be obtained from these variables to dependent variables such as mass flow, void fraction, etc. It should be noted that the equations describing the steady-state performance characteristics are not linearised. The system of equations is integrated numerically with respect to $z$ and has been programmed for a digital computer as described by Van der Walle [2]. The correlation functions are introduced in the programme in the form of sub-routines, which result in a large flexibility.

\section{STABILITY CRITERIA}

As no geometrical data of existing sodium systems were easily available the calculations were performed for the geometry of the boiling water loop of the Technological University of Eindhoven. This makes it also possible to compare the results with those already obtained for boiling water in the same system. While, up till now, these results were only available for naturally circulating conditions, the calculations have been performed without considering the characteristics of any pump. A flow sheet of the system is given in fig. 1 . The main part consists of a pressure vessel with a diameter of $150 \mathrm{~mm}$ and a length of about $3 \mathrm{~m}$, an internal shroud with a diameter of $50 \mathrm{~mm}$ and a length of $2.7 \mathrm{~m}$ and, in the center, an electrically heated stainless steel tube with a diameter of $33.84 \mathrm{~mm}$ and a length of $2.4 \mathrm{~m}$. By the heat transferred to the liquid natural convection occurs, in upward direction in the shroud, and downwards in the vessel. Before entering the shroud the liquid passes through a subcooler.

The hydraulic instabilities that are of interest here are those that are typical for a natural cir culation system. In a forced circulation boiler with very steep head-flow characteristics of the pump, no hydraulic instabilities, such as considered here, have been found. This suggests considering a forced circulation boiler, as shown in figs. 2 and 3 . A pump is present in the downcomer, which pump generates a pressure rise, corresponding with a rise in saturation temperature $\Delta T_{\mathrm{S}}$. The pump measures the fluctuations in mass flow $V_{1, i}$ and translates these variations into a rise in saturation temperature of $\Delta T_{\mathbf{s}, i}$. The index $i$ denotes variations from the steadystate. Now it is assumed that the system is brought into excitation by controlling the pump with a sinusoidal signal corresponding to a desired fluctuation in mass flow $\dot{V}_{1, i}$. The magnitude of $\Delta T_{\mathbf{s}, i}$ (see fig. 3) is dependent upon the difference between $V_{1, i}$ and $\dot{V}_{1, i}$. The dependence may be simply expressed by:

$$
\Delta T_{\mathbf{s}, i}=-H_{\mathrm{p}}\left(V_{1, i}-\stackrel{\circ}{V}_{1, i}\right)
$$




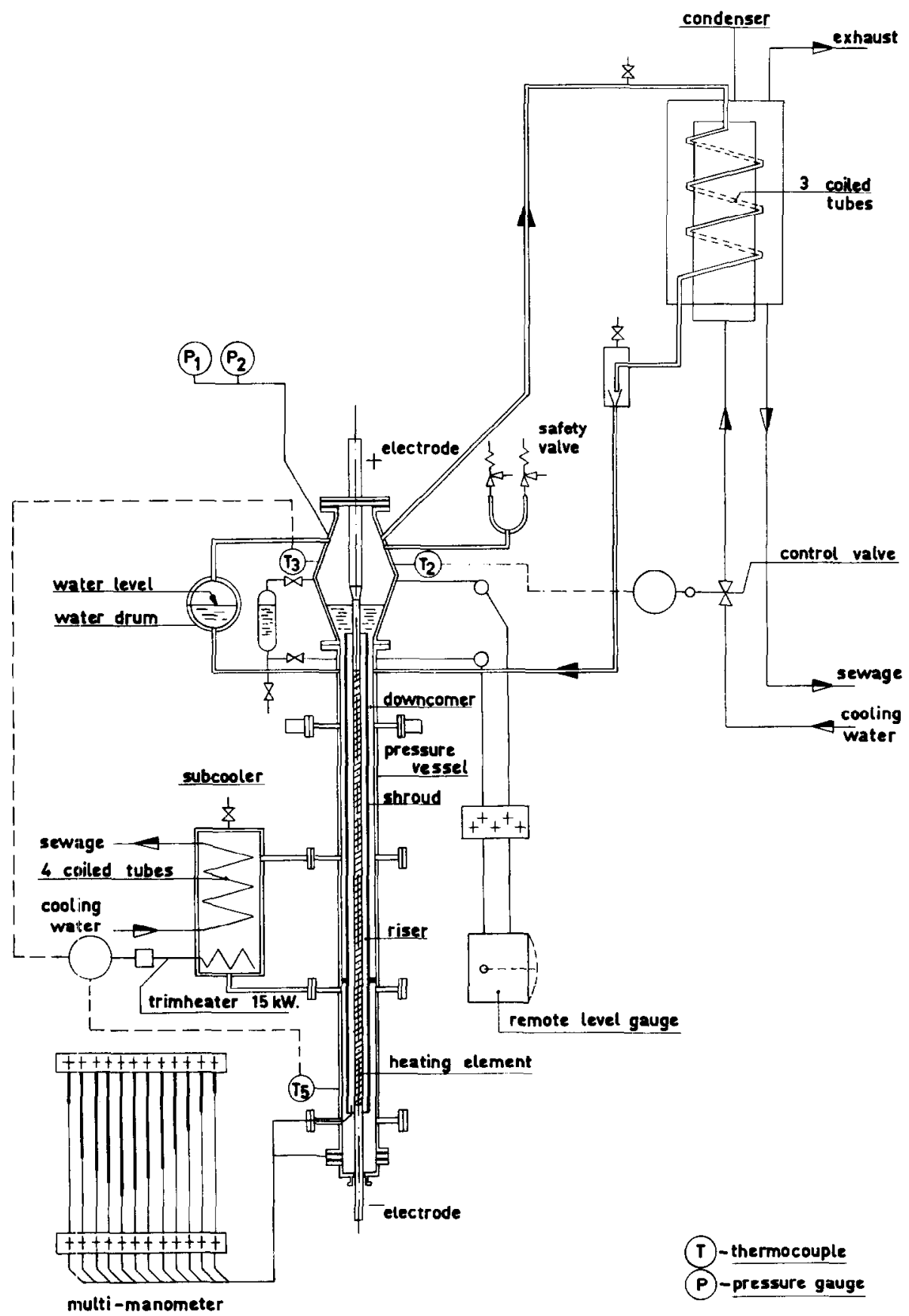

Fig. 1. Flow sheet of the pressurised boiling water loop. 


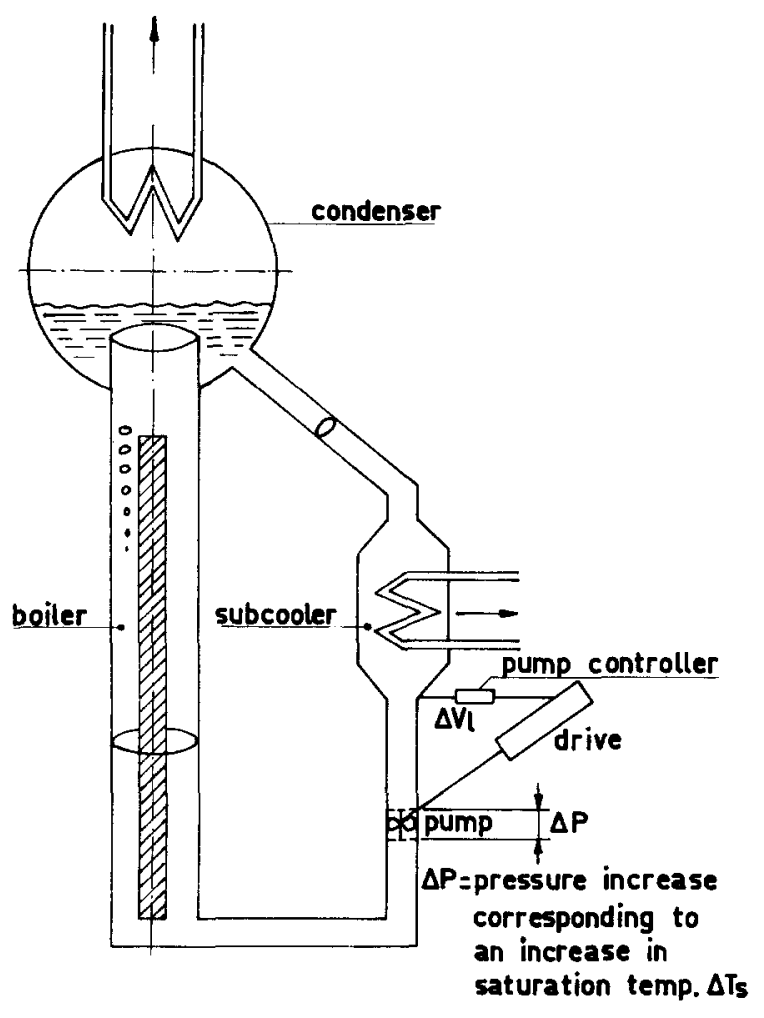

Fig. 2. Forced circulation boiler.

where $H_{\mathrm{p}}$ is a measure of the pump characteristics. The larger $H_{\mathrm{p}}$ becomes, the higher is the pressure rise upon a certain change in mass flow. Actually, $H_{\mathrm{p}}$ is a transfer function and thus a complex quantity. The following transfer functions for the open-loop without a pump and with a cut, as indicated by the broken line in fig. 3 , are defined as:

$G_{1}=\left\{\frac{\left(T_{\mathrm{s}, i}\right)_{\mathrm{do}}}{\left(\dot{T}_{\mathrm{s},}\right)_{\mathrm{in}}}\right\}_{H_{\mathrm{p}}=0}, \quad G_{2}=\left\{\frac{V_{1, i}}{\left(\dot{T}_{\mathrm{s}, i}\right)_{\mathrm{in}}}\right\}_{H_{\mathrm{p}}=0}$

Here $G_{1}$ and $G_{2}$ determine the change in saturation temperature (pressure) and mass flow rate at the outlet of the downcomer upon a variation in saturation temperature (pressure) at the inlet of the heated channel.

The transfer function for the closed-loop from imposed modulation in mass flow to the saturation temperature at the inlet of the channel can then be written as:

$$
\frac{T_{\mathrm{s}, i}}{\dot{V}_{1, i}}=\frac{H_{\mathrm{p}}}{1-G_{1}+H_{\mathrm{p}} G_{2}} .
$$

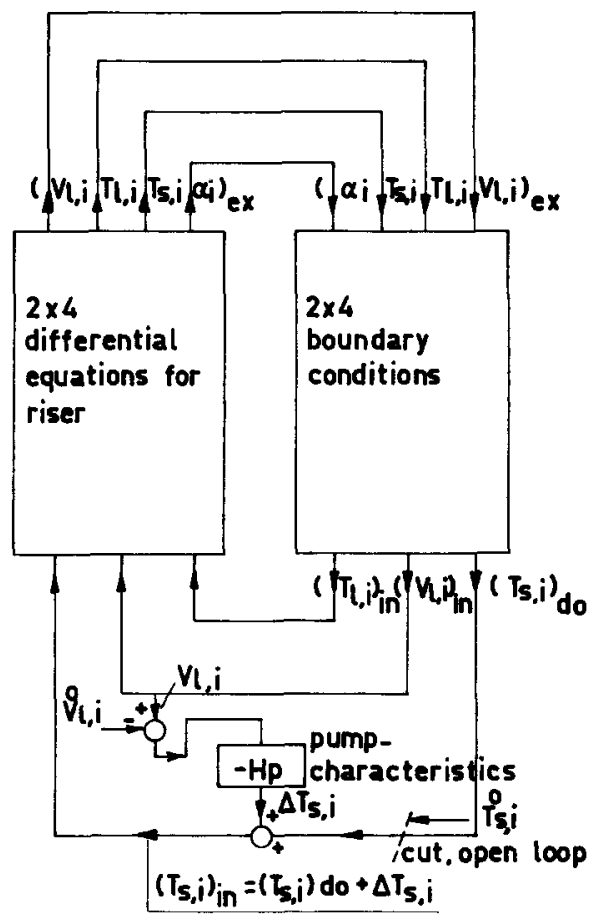

Fig. 3. Block diagram of forced circulation boiler.

An instability condition is obtained when the transfer function defined in eq. (3) approaches infinity. There are two conditions where this is indeed the case:

a) For large values of $H_{\mathrm{p}}$, the system will always be stable, as long as $G_{2}$ does not approach zero. For large values of $H_{\mathrm{p}}$, the transfer function for the closed loop (eq. (3)) approaches the value of $1 / G_{2}$. From the definition of $G_{2}$, it may be concluded that $G_{2}$ will normally never approach zero, unless resonance conditions appear within the boiling channel.

b) For sufficiently low values of $H_{\mathrm{p}}$, the transfer function for the closed loop (eq. (3)) approaches the value of $1 /\left(1-G_{1}\right)$, and an instability condition is obtained when $G_{1}$ becomes +1 for some frequency.

It appears to be advantageous, therefore, to calculate the open loop transfer functions $G_{1}$ and $G_{2}$ and see whether the modulus of $G_{1}$ approaches a condition of +1 , and at the same time whether the phase angle has reached a value of about $0^{\circ}$ or $360^{\circ}$ or whether the modulus of $G_{2}$ has become sufficiently small.

The calculated steady-state characteristics and the threshold channel powers for the onset of 
flow oscillations in the boiling water system, calculated by means of $G_{1}$ and $G_{2}$, compared quite well with experimentally determined values, see Spigt [1]. Furthermore, it was shown that in a boiling water system three different types of flow oscillations may occur, with frequencies of roughly $0.03,1$ and $15 \mathrm{cps}$.

\section{DESCRIPTION OF THE CONDITIONS}

The most important geometrical and hydrodynamic data of the boiling loop are given in table 1.

Table 1

Geometric and hydrodynamic data of the boiling loop of the Technological University of Eindhoven.

\begin{tabular}{|l|l|l|}
\hline Quantity & Units & Value \\
\hline length of channel & $\mathrm{m}$ & 2.70 \\
length of heated part of channel & $\mathrm{m}$ & 2.4 \\
length of downcomer & $\mathrm{m}$ & 4.42 \\
cross- sectional area of channel & $\mathrm{m}^{2}$ & 0.00106 \\
cross-sectional area of downcomer & $\mathrm{m}^{2}$ & 0.00958 \\
area of water surface in condenser & $\mathrm{m}^{2}$ & 0.495 \\
volume of subcooler & $\mathrm{m}^{3}$ & 0.0330 \\
condenser volume & $\mathrm{m}^{3}$ & 0.1454 \\
part of the condenser occupied by & & \\
steam & - & 0.75 \\
height of water level above channel & & \\
inlet & $\mathrm{m}$ & 2.74 \\
outer diameter of heating element & $\mathrm{m}$ & 0.03384 \\
hydraulic diameter of channel & $\mathrm{m}$ & 0.01616 \\
inner diameter of shroud & $\mathrm{m}$ & 0.05 \\
pressure loss coefficient at channel & & \\
inlet & - & 1.4 \\
pressure loss coefficient at channel & & 0 \\
exit & - & 0 \\
\hline
\end{tabular}

The calculations have been performed at three pressures, $1,8.7$ and $16.4 \mathrm{~atm}$, with no subcooling at the inlet. The physical constants for boiling sodium were derived from Spiller [3]. The data used are given in table 2.

As no correlation for the slip ratio and two phase friction were available for boiling sodium, the correlations for boiling water at the same system pressure were used. For the slip ratio the correlation of Zuber and Findlay [4], based on experimental data of the Technological University of Eindhoven, have been applied. The correlation of Martinelli-Nelson as formulated by Jones [5], has been used for the calculation of the two phase friction losses.

It is known from experimental data that appreciable superheats of the liquid phase can occur in boiling sodium. As already mentioned in the theory it is possible to simulate this phenomenon by the choice of $\kappa$. This can easily be done by varying a constant $F_{1}$, the superheat parameter, in the correlation for $\kappa$. The influence of the amount of superheat on the results has been calculated at a system pressure of 16.4 atm. At this pressure the superheat parameter $F_{1}$ has been varied from 500 to 50 which corresponds with a variation in the superheat at the exit of the channel of 2 to $15^{\circ} \mathrm{C}$. In all the other calculations $F_{1}$ was 500 .

The steady-state results have been calculated as a function of channel power. In the following results of the calculations of the recirculation rate, the void fraction and the temperatures of the liquid and vapour phase along the channel are given.

The harmonic analysis has been carried out for a limited number of channel powers in the frequency range of 0.03 to $17 \mathrm{cps}$. Results are

Table 2

Physical constants for sodium [3].

\begin{tabular}{|l|l|c|c|c|}
\hline Quantity & Units & & & \\
\hline pressure & atm, abs & 1 & 8.7 & 16.4 \\
saturation temperature & ${ }^{\circ} \mathrm{C}$ & 880 & 1180 & 1300 \\
liquid density & $\mathrm{kg} / \mathrm{m}^{3}$ & 739.5 & 629 & 3.86 \\
vapour density & $\mathrm{kg} / \mathrm{m}^{3}$ & 0.28 & 2.22 & 1445 \\
specific heat & $\mathrm{J} / \mathrm{kg}{ }^{\circ} \mathrm{C}$ & 1285 & $3.9455 \times 10^{6}$ \\
heat of evaporation & $\mathrm{J} / \mathrm{kg}$ & $3.415 \times 10^{6}$ & $3.106 \times 10^{6}$ & 27.75 \\
heat conduction coefficient & $\mathrm{W} / \mathrm{m}^{\circ} \mathrm{C}$ & 47.9 & 33.4 & 0.000140 \\
dynamic viscosity & $\mathrm{Nm} / \mathrm{sec}^{2}$ & 0.000169 & 0.000145 & -0.281 \\
variation of liquid density with saturation & $\mathrm{kg} / \mathrm{m}^{3}{ }^{\circ} \mathrm{C}$ & -0.256 & -0.2625 & 0.015 \\
temperature & $\mathrm{kg} / \mathrm{m}^{3}{ }^{\circ} \mathrm{C}$ & 0.0025 & 0.012 & 7780 \\
$\quad$ variation of vapour density with saturation & $\mathrm{N} / \mathrm{m}^{2}{ }^{\circ} \mathrm{C}$ & 950 & 4800 & \\
variation of vapour pressure with saturation \\
temperature & & & & \\
\hline
\end{tabular}


given of the calculation of $G_{1}$ and $G_{2}$ and the closed loop transfer function from channel power to the liquid velocity at the inlet. From these calculations the instability threshold channel power and the frequency of the resulting flow oscillations are deduced.

\section{RESULTS}

\subsection{Results of the steady-state calculations}

The calculated recirculation rate $V_{c i}$ (i.e. the liquid velocity $V$ at the channel inlet) in meters per second and the calculated void fraction at the

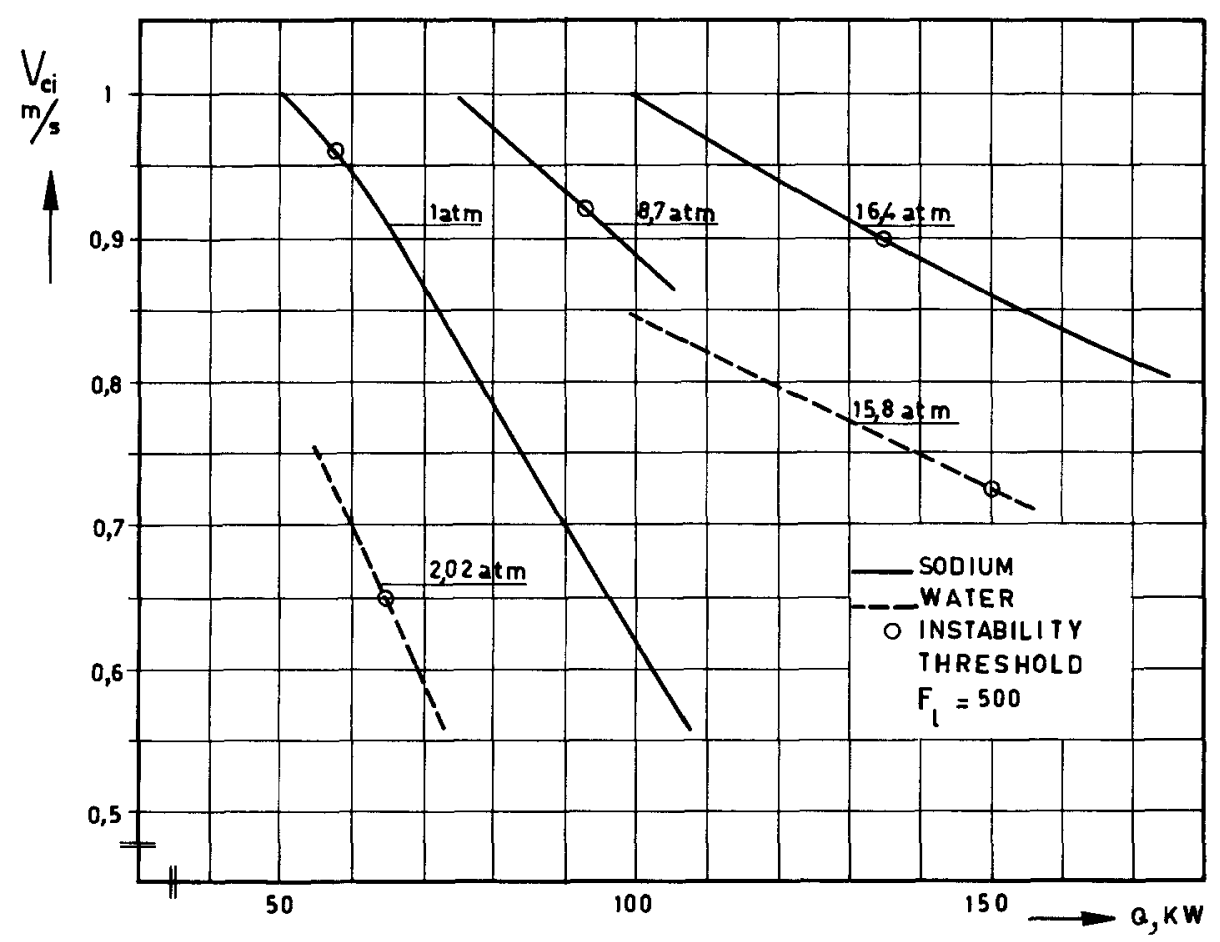

Fig. 4. Recirculation rate as a function of channel power.

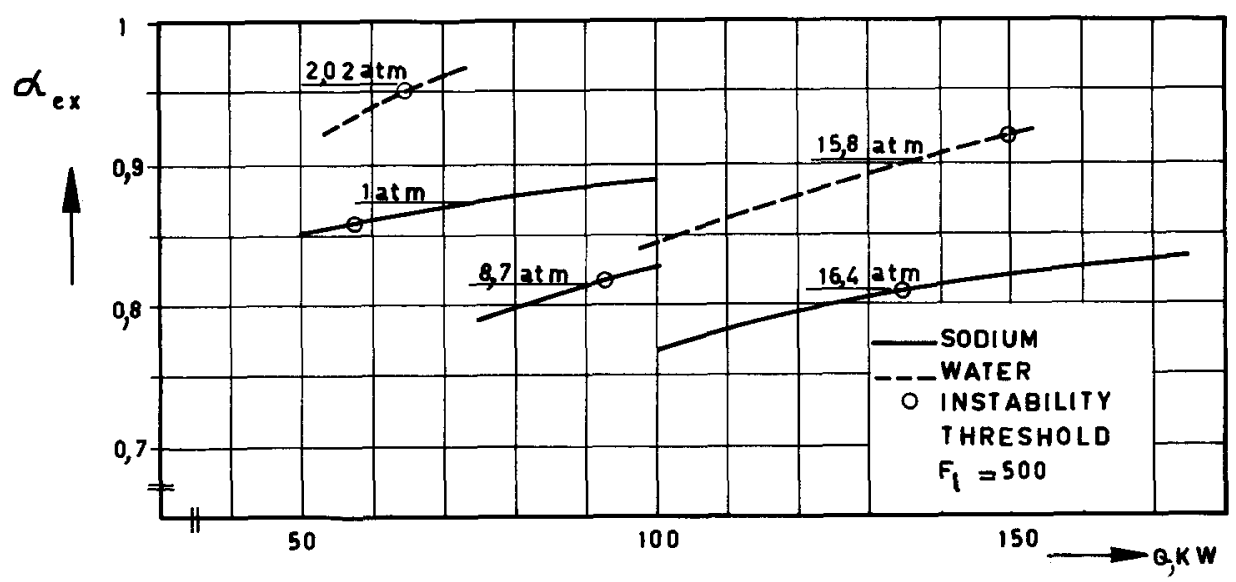

Fig. 5. Exit void fraction as a function of channel power. 
exit of the channel $\alpha_{\mathrm{ex}}$ are shown in figs. 4 and 5 as a function of the channel power $Q$ for three system pressures. As is shown, the recirculation rate decreases with increasing channel power. This means that an incremental increase in channel power causes the frictional and acceler- ation losses to increase by a larger amount than the driving head. The increase in void fraction with increasing channel power is caused by the increased vapour production. It can be shown that at first approximation $\alpha /(1-\alpha)$ is proportional to the channel power which explains the

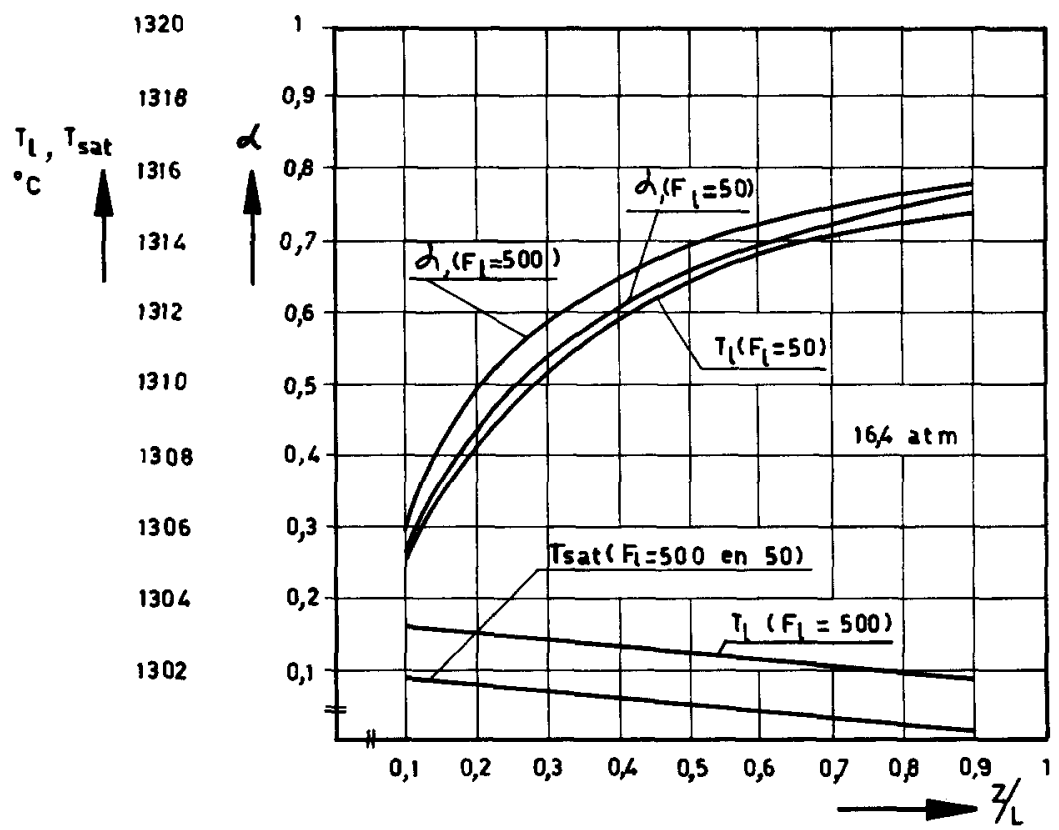

Fig. 6. Void fraction and temperatures along the channel for two values of the superheat parameter $F_{1}$.

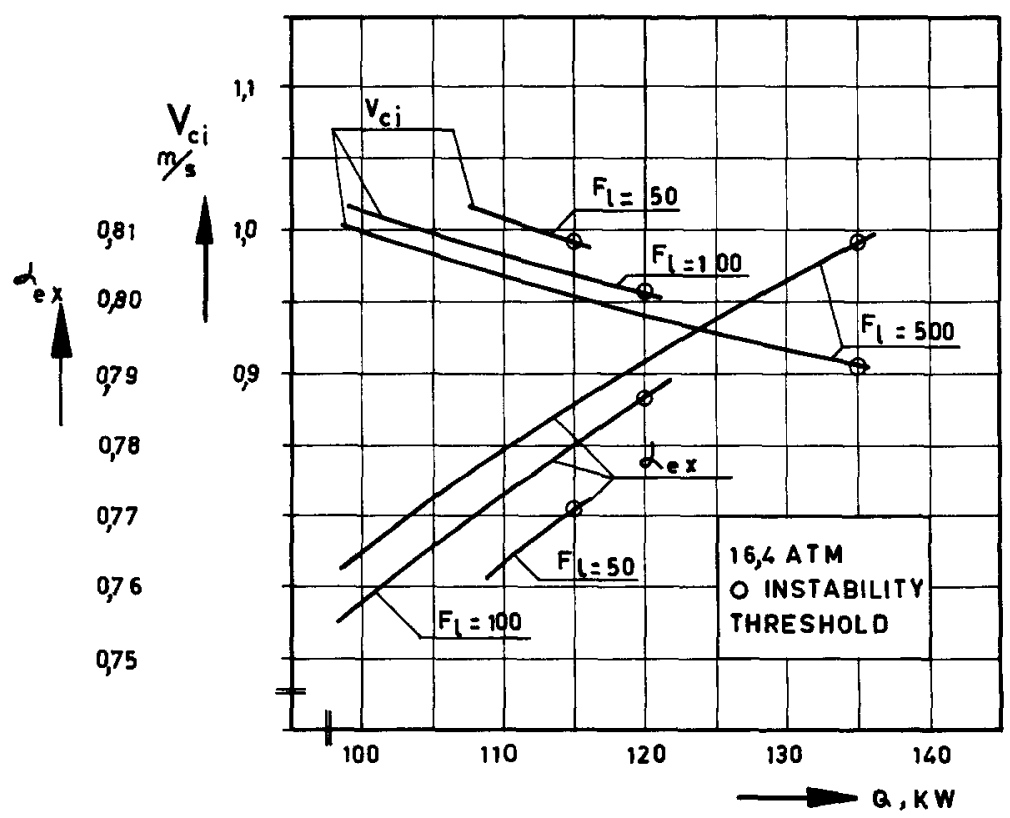

Fig. 7. Influence of the superheat parameter on $\alpha_{\mathrm{ex}}$ and $V_{\mathrm{ci}}$. 


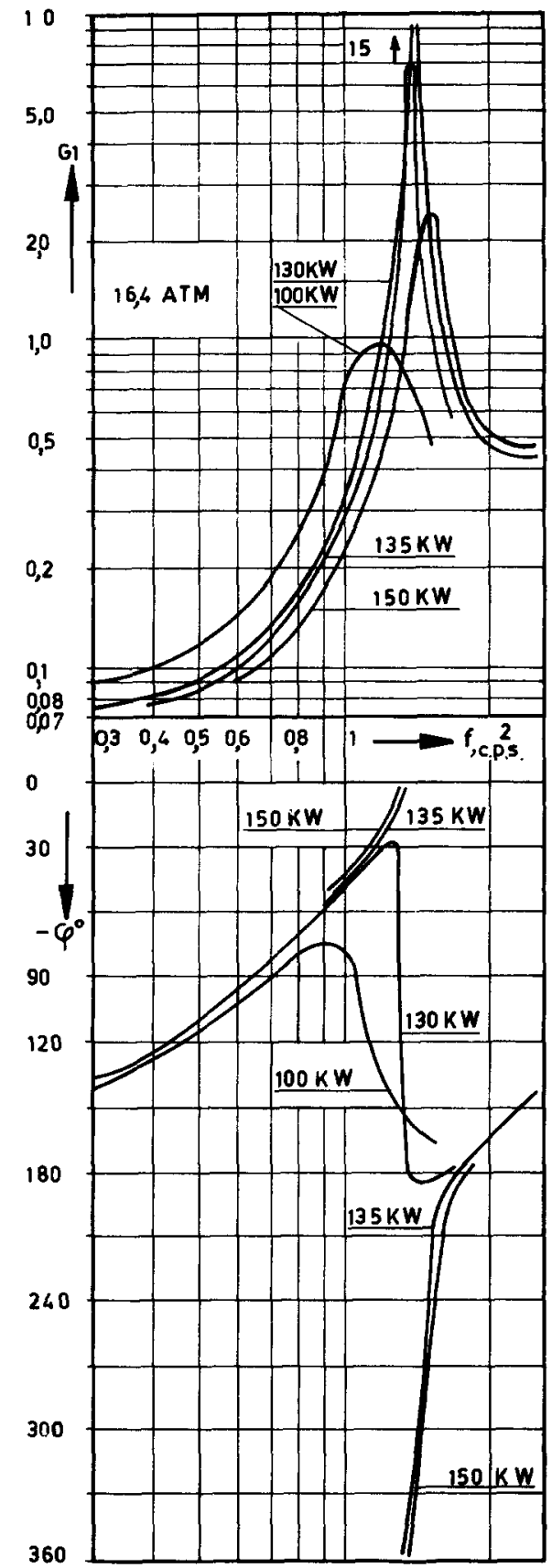

Fig. 8. Open-loop transfer functions, low frequency range.

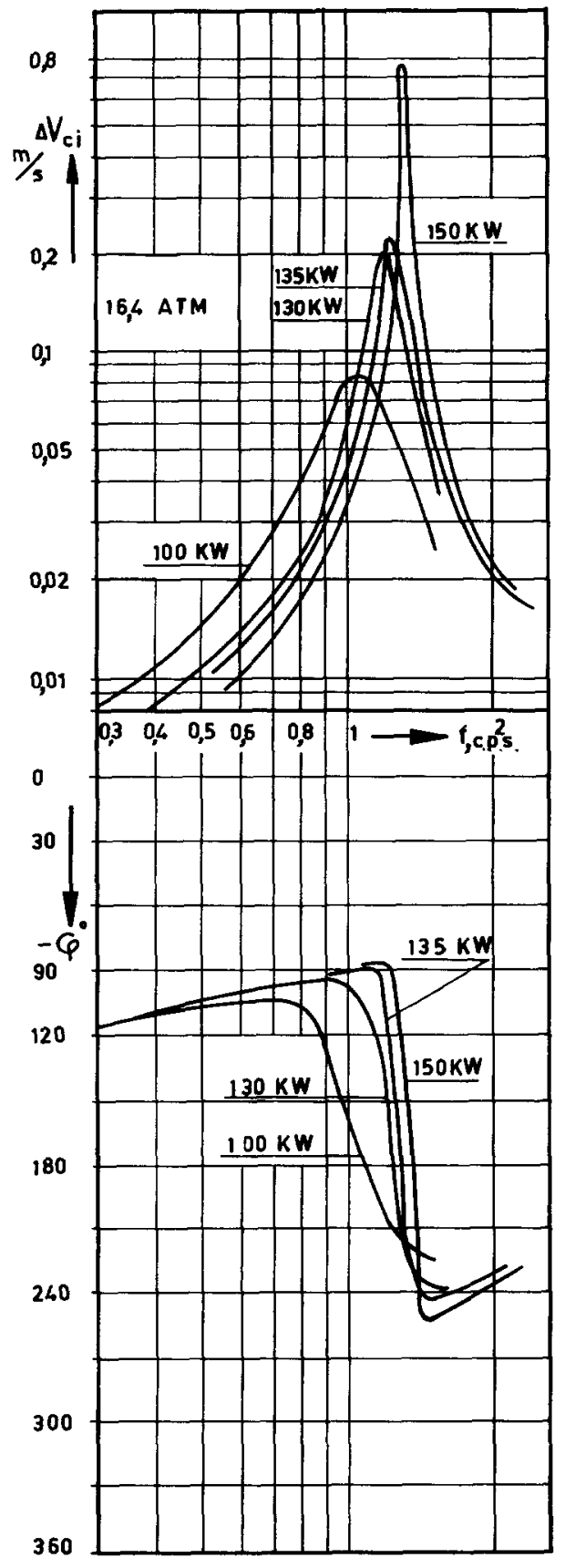

Fig. 9. Closed-loop transfer functions, low frequency range. 
decreasing slope of the void fraction versus power curves with increasing channel power. An increase in system pressure results in a decrease in void fraction, which is largely due to the increase in specific density with pressure. This decrease in void fraction results in a decrease in the driving head and corresponds, ther efore, to an increasing circulation rate with a decrease in system pressure. For comparison some results for the boiling water system are also given. Owing to the lower value of the heat of evaporation for water, the void fraction for the boiling water system is higher and the recirculation rate lower than for the boiling sodium system.

In fig. 6 the distribution along the channel of the void fraction $\alpha$, the liquid temperature $T_{1}$ and the saturation temperature $T_{\text {sat }}$ are given for a system pressure of $16.4 \mathrm{~atm}$, a channel power of $110 \mathrm{~kW}$ and two values of the superheat parameter $F_{1}$. As is shown, the liquid superheat changes from 1.8 to $14.4^{\circ} \mathrm{C}$ for a change in $F_{1}$ from 500 to 50 . At $F_{1}=50$ there is more heat stored in the sodium than at $F_{1}=500$, which results in lower values of the void fraction for a lower $F_{1}$. The variation in pressure (saturation temperature) along the channel is, practically spoken, independent of the liquid superheat.

In fig. 7 finally, the influence is shown of $F_{1}$ on the recirculation rate and on the exit void fraction versus channel power curves. The in- crease in void fraction with decreasing liquid superheat corresponds with the decrease in recirculation, as was the case with the influence of system pressure (see figs. 4 and 5 ).

\subsection{Results of the slability calculations}

The open loop transfer functions $G_{1}$ and $G_{2}$ (i.e. the phase angle and the modulus) as well as the transfer function for the closed loop from the channel power to the recirculation rate have been calculated for the three system pressures mentioned before and a number of channel powers. The results for a system pressure of 16.4 atm are presented in figs. 8-11.

In figs. 8 and 9 the open and closed loop char acteristics have been plotted for a frequency range of 0.3 to 2 cps for different channel powers. In the upper parts of the diagrams the modulus has been plotted and in the lower parts the phase shift of the responding signal with respect to the oscillation of the excitation. In the plot of the open loop characteristics, $G_{1}$, it is shown that an unstable condition is passed when progressing from 130 to $135 \mathrm{~kW}$ channel power. At $130 \mathrm{~kW}$ the modulus of $G_{1}$ becomes larger than unity but the phase angle does not approach the value of $0^{\circ}$ or $360^{\circ}$. At $135 \mathrm{~kW}$ the modulus of $G_{1}$ is larger than unity and the phase angle becomes zero at a frequency of $1.32 \mathrm{cps}$, which indicates that the system is unstable.

Here it should be pointed out that conditions

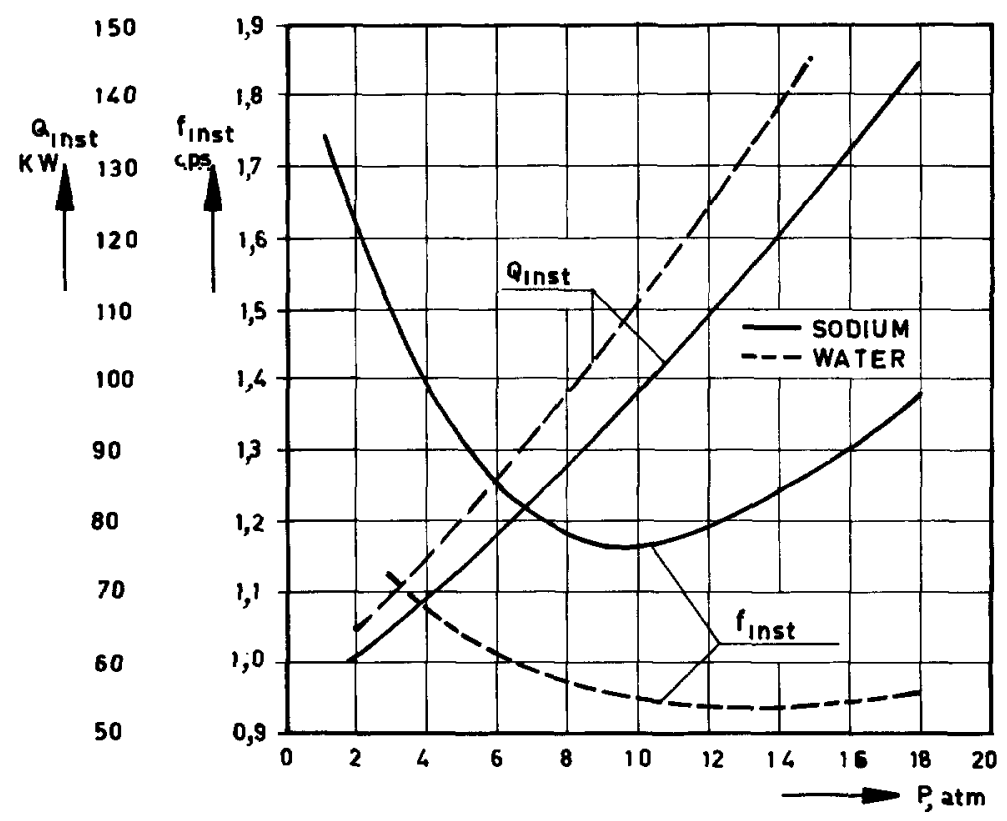

Fig. 10. Influence of the system pressure on $Q_{\text {inst }}$ and $f_{\text {inst }}$. 


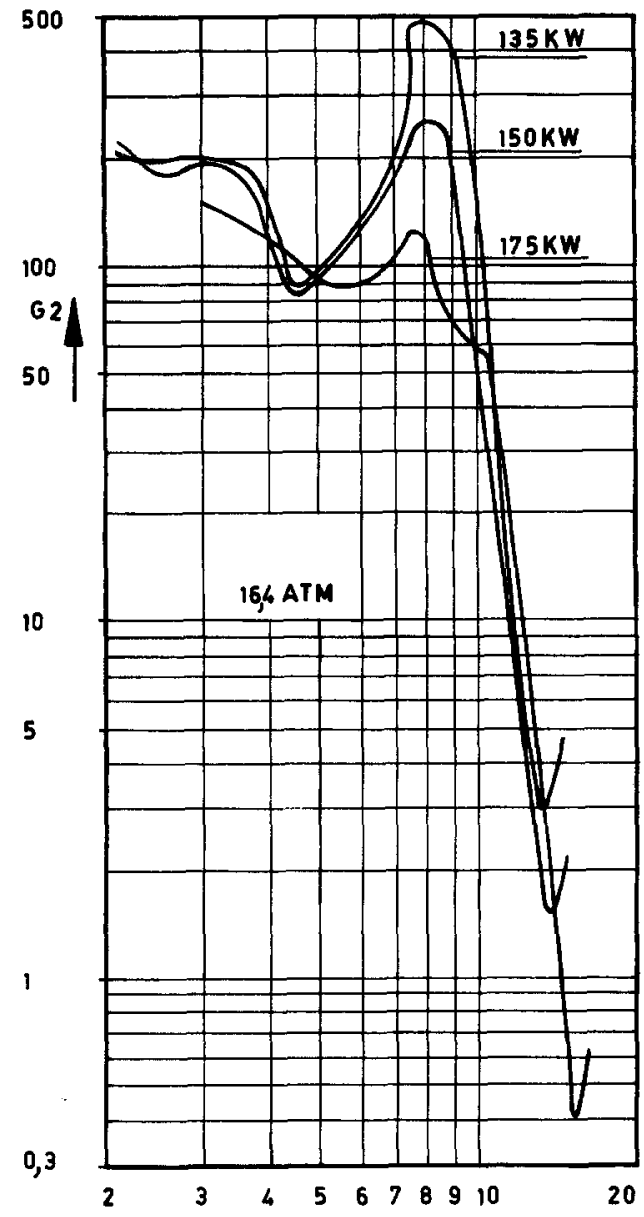

Fig. 11. Open-loop transfer function $G_{2}$, high frequency range.

of $G_{1}$ in which the argument is zero but the modulus is in excess of unity are not unstable in the linearised approximations. However, these conditions are generally termed "conditionally stable" conditions in control theory, as large amplitude fluctuations tend to decrease effectively the modulus with only small changes in the phase angle because of non-linear saturation effects. In practice these conditions are therefore only stable for very small oscillations and tend to develop self-sustained finite amplitude oscillations. Furthermore, by calculating the conditions between 130 and $135 \mathrm{~kW}$ channel power a condition will be found where the condition $G_{1}=1$ is exactly fulfilled.

The closed loop response of the natural circulation loop to a modulation of the channel power is shown in fig. 9. Vertically the fluctuation in inlet velocity per $\mathrm{kW}$ power modulation is plotted. A comparison between the open and closed loop results shows a strongly peaked behaviour in $V_{\mathrm{c} i}$ at the frequency at which the phase angle for $G_{1}$ passes $0^{\circ}$. Also in the closed loop, a condition will be found corresponding to $G_{1}=1$ where the amplitude ratio becomes infinite. Also for the other system pressures the instability threshold was clearly indicated by the transition of the phase angle curve of $G_{1}$ at a certain channel power from a closed curve to an open one. The natural circulation threshold data are summarised in fig. 10. For comparison the data for boiling water are also given. The general behaviour for the boiling sodium system is roughly the same as for the boiling water system. The resonance frequency is appreciably higher than in the case of water, i.e. around 1.4 cps instead of around $1.0 \mathrm{cps}$. This is probably due to the lower vapour density of sodium. Furthermore, the resonance frequency shifts appreciably with system pressure whereas in boiling water this frequency change is much less pronounced. Finally, in the boiling sodium case a pronounced minimum in the resonance frequency exists whereas in the boiling water case this minimum is much less pronounced.

In fig. 11 the modulus of the open loop transfer function $G_{2}$ is presented for the frequency range from 2 to $17 \mathrm{cps}$ and a system pressure of $16.4 \mathrm{~atm}$. The modulus of the transfer function $G_{2}$ shows a sharp dip at the higher frequencies. This indicates the approach to a forced circulation instability at a frequency of about $15 \mathrm{cps}$ and at an appreciably higher channel power than corresponds to the hydraulic instability of the natural circulation system. The minimum values attained for $G_{2}$ are $3.12,1.56$ and 0.40 for a channel power of 135,150 and $175 \mathrm{~kW}$, respectively. As the forced circulation loop becomes unstable for $G_{2}=0$ (see section 3), it is evident that the instability is attained at a channel power slightly above $175 \mathrm{~kW}$. The curves for $G_{1}$ in this frequency range (fig. 12) show that the natural circulation loop exhibits also a tendency to instability although at a somewhat lower frequency. The nature of this instability is, however, undoubtedly of the same origin as that of the forced circulation loop. In [1] it is shown that this instability is characterised by a standing wave oscillation with zero velocity fluctuation at the inlet.

The influence of the liquid superheat on the instability threshold for a natural circulation boiling sodium system has been evaluated at a system pressure of $16.4 \mathrm{~atm}$. The results of these calculations are summarised in fig. 13. 

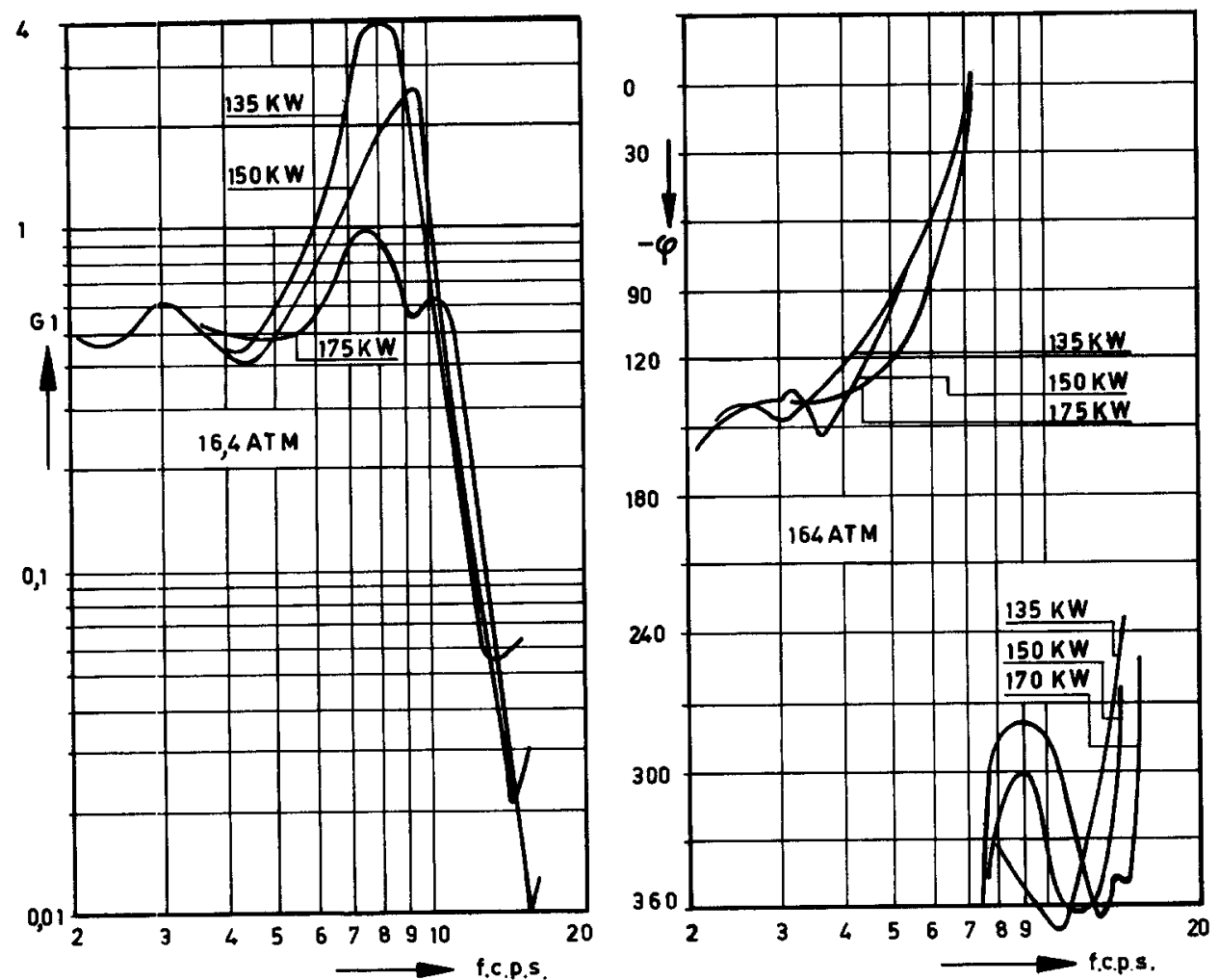

Fig. 12. Open-loop transfer function $G_{1}$, high frequency range.

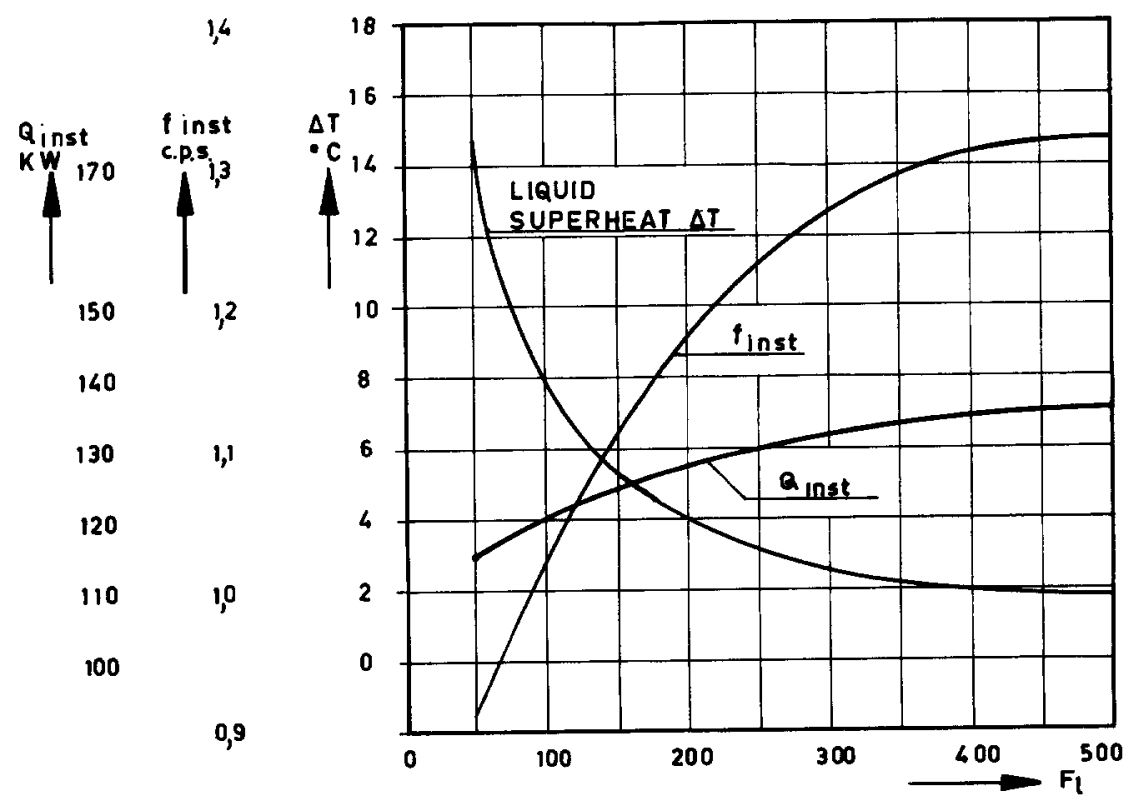

Fig. 13. Influence of the superheat parameter on $Q_{\text {inst }}, f_{\text {inst }}$ and the liquid superheat $\Delta T$. 
Horizontally the superheat parameter $F_{1}$ has been plotted. Vertically the corresponding liquid superheat $\Delta T$, the instability threshold channel power $Q_{\text {inst }}$ and the resonance frequency $f_{\text {inst }}$ have been plotted. As can be concluded from this figure the channel power for instability decreases with an increase in liquid superheat, although the total void volume present in the channel decreases (see figs. 6 and 7). Furthermore, there is an appreciable effect of liquid superheat on the resonance frequency. When the density of the fluid in the channel decreases, there will be a decrease in the resonance frequency. This is in agreement with the results of experiments carried out in boiling water tests, see Spigt [1]. It is evident that the phenomenon of liquid superheat should be taken into account in a stability analysis in case appreciable superheats are found to occur.

\section{CONCLUDING REMARKS}

The present study seems to indicate that the relatively large differences in physical properties between liquid sodium and water do not lead to difficulties in applying the theoretical models that have been developed for water systems to liquid sodium. Experimental verification of the predicted results is, however, required.

In boiling sodium systems the same type of hydraulic instabilities are found as in boiling water systems, although the power at which the loop becomes unstable is lower in the case of liquid sodium and the resonance frequency higher.

As could be expected, the influence of liquid superheat on the dynamic behaviour of the loop is rather large. This should be well kept in mind in predicting loop behaviour under transient conditions.

\section{REFERENCES}

[1] C.L.Spigt, On the hydraulic characteristics of a boiling water channel with natural circulation, Thesis Technological University Eindhoven (1966).

[2] F. Van der Walle and H. J. Lamein, A digital computer programme for the non-linear steady-state and quasi-linear dynamic calculation of boiling hydraulic loops, Report Rescona Ltd., The Netherlands, No. 64-10 (1966).

[3] K. H. Spiller, Physikalisch-thermische Eigenschaften von $\mathrm{Na}-, \mathrm{K}-$ und NaK-Legierungen im Temperaturbereich zwischen Siedepunkt und etwa $1300^{\circ} \mathrm{C}$. Euratom report Nr. EUR 357,d (1963).

[4] N.Zuber and J.A. Findlay, Average volumetric concentration in two-phase flow systems, Trans. ASME. J. Heat Transfer 87 (1965) 453.

[5] A. B. Jones and D. G. Dight, Hydrodynamic instability of a boiling channel, Reports of Knolls Atomic Power Laboratory, Schenectady, KAPL 2170 (1961), 2208 (1962), 2290 (1963), 3070 (1964). 